\title{
Helicobacter pylori infection presenting as childhood recurrent headache: A case report
}

\author{
Madhura Shivalingaiah ${ }^{1}$, Mallesh Kariyappa ${ }^{2}$, Anil Kumar Hanumanna ${ }^{3}$, Kalpana Ramesh Yelsangikar ${ }^{1}$ \\ From ${ }^{1}$ Senior Resident, ${ }^{2}$ Professor, ${ }^{3}$ Assistant Professor, Departments of Pediatrics, Bengaluru Medical College and Research Institute, Bengaluru, \\ Karnataka, India
}

Correspondence to: Dr. Mallesh Kariyappa, 210/A-3, Sharavathi Block, National Games Village, Koramangala, Bengaluru - 560047 , Karnataka, India. E-mail: drmalleshk2@gmail.com

Received - 12 April 2019

Initial Review - 09 May 2019

Accepted - 03 June 2019

\begin{abstract}
Headache in children and adolescents is common and there is a steady increase in the incidences in recent years. Migraine has been attributed as the most common cause of recurrent headache under the age of 6 years. Migraine is reported in 3.9\% of children aged $7-15$ years which increases from $1.7 \%$ in 7 years old to $5.3 \%$ in 15 years old. Many studies have focussed on the association between headache and Helicobacter pylori infection which is acquired early in the childhood beyond the age of 10 years through fecal-oral route transmission. Here, we report a case of $H$. pylori infection in a 13-year-old female child who presented with a history of recurrent headache refractory to standard treatment. Later, the child was diagnosed to have $H$. pylori gastritis. Headache responded to 4 weeks course of $H$. pylori eradication therapy.
\end{abstract}

Key words: Antral polyp, Helicobacter pylori, Migraine, Recurrent headache

A steady increase in the number of incidences regarding headache in children and adolescents has been observed in recent years. Migraine is the most frequent type of recurrent headache under the age of 6 years [1]. Migraine is reported in $3.9 \%$ of children aged $7-15$ years, which increase from $1.7 \%$ in 7 years old to $5.3 \%$ in 15 years old [2]. Migraine is characterised by episodic attack that may be moderate to severe in intensity, focal in nature, have a throbbing quality and may be associated with nausea, vomiting, light sensitivity and sound sensitivity. Compared to adults, pediatric migraine is shorter in duration and often has bilateral, bifrontal in the point of location. Migraine is classified into four types: Migraine with aura (classic migraine), migraine without aura, and other types of migraine and cluster headache. Migraine without aura is the most common type. The duration of headache is usually $4-72 \mathrm{~h}$ in adults and $1-72 \mathrm{~h}$ in children. The migraine that persists beyond $72 \mathrm{~h}$ is classified as status migrainosus [3]. In recent years, researchers have explored the potential role of Helicobacter pylori infection in the pathogenesis of migraine.

H. pylori is a Gram-negative spiral bacteria found in association with gastric epithelium and is acquired early in childhood beyond the age of 10 years, with the major route of transmission being fecal-oral route. Infection through $H$. pylori results in persistent activation of the immune system, resulting in triggering of local and systemic release of a wide variety of vasoactive substances which has been attributed in the pathology of headache [4,5]. The most commonly implicated vasoactive substance are calcitonin gene-related peptide (CGRP) and serotonin. Stimulation of serotonergic cells causes increased cerebral blood flow which is considered as a cause of pain in migraine. Only a limited literature is available focusing on the incidences of $H$. pylori infections causing recurrent headache in children, especially from South India. The present case focused on elaborating the pathological association of $H$. pylori infection in children causing recurrent headaches.

\section{CASE REPORT}

A 13-year-old female child second born to the second degree consanguineously married couple presented with a history of headache on and off for 6 months. There was a history of vomiting and photophobia and sometimes non-characteristic abdominal pain during headache. There was no history of headache in the family. The child was developmentally normal for the age and was immunized up to date.

On physical examination, her height was $143 \mathrm{~cm} \mathrm{(} 3^{\text {rd }}$ and $10^{\text {th }}$ centile), weight was $34 \mathrm{~kg}\left(10^{\text {th }}\right.$ and $25^{\text {th }}$ centile $)$, and body mass index was $16.6\left(10^{\text {th }}\right.$ and $25^{\text {th }}$ centile $)$. His pulse rate was $84 / \mathrm{min}$, respiratory rate was $18 / \mathrm{min}$, and blood pressure was $110 / 70 \mathrm{mmHg}$. Systemic examination was unremarkable. Laboratory investigation revealed hemoglobin of $12.6 \mathrm{~g} / \mathrm{dl}$ and other parameters were within normal limits. The child was evaluated for headache. Ocular, sinus, and auditory evaluations revealed no abnormalities. C-reactive protein and erythrocyte sedimentation rate were done to rule out vascular causes of headache which came normal. Neuroimaging (computed 
tomography brain) was done which was also normal. Psychiatrist consultation suggested no psychiatric intervention. Migraine with cyclical vomiting syndrome (CVS) was diagnosed after consultation with neurologist.

For prophylaxis, flunarizine tablet was used along with naproxen sodium during the period of headache; however, the frequency and severity of headache remained constant. In view of the refractory headache, often associated abdomen pain, upper gastrointestinal (GI) endoscopy was performed which revealed the presence of antral polyp. The specimen obtained from the antral biopsy was tested with rapid urease test which gave positive results suggesting the presence of $H$. pylori infection. H. pylori eradication treatment was initiated with clarithromycin $250 \mathrm{mg} \mathrm{BD}$, tinidazole $500 \mathrm{mg} \mathrm{BD}$, and lansoprazole $30 \mathrm{mg} \mathrm{BD}$ for 14 days followed by lansoprazole for another 2 weeks. The child showed symptomatic improvement in 4 days and symptom free at the end of 4 weeks and the latest follow-up.

\section{DISCUSSION}

Headache is a common complaint in children and adolescents. Headache can be a primary problem or secondary problem. Migraine is the most common form of primary headache and most common cause of recurrent headache under the age of 6 years [1]. Headache can be mild to severe and may have one or all symptoms such as nausea, vomiting, photophobia and phonophobia. Aura associated with migraine is a neurologic warning that migraine is going to occur. Aura may be visual, sensory or dysphasic [2].

CVS is a functional disorder that is considered to be a manifestation of migraine diathesis. It is characterized by stereotypical episodes of severe nausea and vomiting lasting several hours or days with a return to baseline health in between episodes. Diagnostic criteria for the diagnosis of CVS, recommended by North American society for pediatric gastroenterology, hepatology, and nutrition, are as follows [6]: All of the criteria must be met to meet this consensus definition of CVS.

- At least five attack in any interval or a minimum of three attacks during a 6-month period

- Episodic attacks of intense nausea and vomiting lasting from $1 \mathrm{~h}$ to 10 days and occurring at least 1 week apart

- Stereotypical pattern and symptoms in the individual patient

- Vomiting, during attacks, occurs at least 4 times in an hour for at least $1 \mathrm{~h}$

- Return to baseline health between episodes

- Not attributed to another disorder.

Many factors such as genetics, food and medication, sleep disorder, stress, different smell, menstruation, trauma, and alcohol have been recognized as triggering factors for migraine [7]. Pain in migraine occurs as a result of activation of the trigeminal vascular system. Neuropeptides such as CGRP, substance P, and vasoactive intestinal peptide are released when trigeminal fibers or trigeminal ganglion is activated. This release of neuropeptides has been proposed as a cause of pain mechanism in migraine.
CGRP is a powerful vasodilator which produces dilatation of dural vessels and an increase in blood flow [8]. Furthermore, studies have shown that serotonin plays a significant role in the causation of headache [9].

In recent years, the role of infectious agents, immune responses on migraine have gained more attention. Many studies have shown the association between headache and $H$. pylori infection. Tunca et al. in their study found a significant association between migraine and $H$. pylori infection and concluded that $H$. pylori should be examined in migrainous patients and eradication of infection may be helpful for the treatment of the disease [10]. Another study by Su and Zhou suggested a frequent association of $H$. pylori infection with migraine [11].

The research explained that GI neuroendocrine cells such as enterochromaffin cells can secrete serotonin and some other factors that stimulate the synthesis of serotonin can cause central nervous system perturbation through brain-gut axis which can demonstrate that the most migrainous patients are associated with the GI disorder. It has been suggested that the pathogenic role of $H$. pylori infection in migraine is based on the relationship between the host immune response against the bacterium and the chronic release of vasoactive substances [12]. During infection, bacteria releases toxins in infected tissue, thus promoting the special cascade of events related to host immune response resulting in alterations of vascular permeability. Thus, prolonged oxidative injury caused by persistent infection and release of vasoactive substances might be involved in local cerebral blood circulation changes during migraine attacks [12].

Hence, prompt identification of $H$. pylori infection should be done in all cases of migraine. In the present case, the child had received standard treatment for migraine without relief. Hence, she was evaluated for $H$. pylori infection. Various tests are available for diagnosis of $H$. pylori infection. Endoscopic antral biopsy for rapid urease test, histology, and culture is the gold standards in the diagnosis. Other tests include serology, breath urea test, and polymerase chain reaction. The urea breath test has sensitivity and specificity of $100 \%$ and $98 \%$, respectively. Rapid urease test on biopsy specimen has a sensitivity of $90-95 \%$ and specificity of $98 \%$ [13]. In the present case, the child was subjected to upper GI endoscopy which showed antral polyp. The antral biopsy specimen was positive for $H$. pylori infection. Thus, the diagnosis of $H$. pylori infection was confirmed and $H$. pylori eradication therapy was initiated. Various drugs used for the treatment of $H$. pylori infection include amoxicillin $50 \mathrm{mg} / \mathrm{kg} /$ day, metronidazole $20 \mathrm{mg} / \mathrm{kg} /$ day, tinidazole $20 \mathrm{mg} / \mathrm{kg} /$ day, clarithromycin $15 \mathrm{mg} / \mathrm{kg} /$ day, omeprazole 20 mg OD ( $<10$ years) and $20 \mathrm{mg}$ BD ( $>10$ years), colloidal bismuth subcitrate $480 \mathrm{mg} / 1.73 \mathrm{~m}^{2} /$ day, and furazolidone $6-8 \mathrm{mg} / \mathrm{kg} /$ day [13].

\section{CONCLUSION}

Any child presenting with recurrent chronic headache should be evaluated for $H$. pylori infection, especially older children and adolescents. Early initiation of $H$. pylori eradication 
therapy helps in resolution of symptoms of headache, decreases morbidity, school absenteeism, fecal-oral spread, complications of peptic ulcer disease, and possibly long-term complications like adenocarcinoma.

\section{ACKNOWLEDGMENT}

We acknowledge Dr. Sarala Sabapathy, HOD, Department of Pediatrics, Dr. Anusha and Dr. Deepthy Alice Varghese, Junior Residents, Bangalore Medical College and Research Institute, Bengaluru, and the patient herself and her parents for permitting us to report this case.

\section{REFERENCES}

1. Raieli V, Eliseo M, Pandolfi E, La Vecchia M, La Franca G, Puma D, et al. Recurrent and chronic headaches in children below 6 years of age. J Headache Pain 2005;6:135-42.

2. Ray M. Headaches and migraine in children. In: Parthasarathy A, editor. IAP Textbook of Paediatrics. $5^{\text {th }}$ ed. New Delhi: Jaypee Publishers; 2013. p. 358-61.

3. Hershey AD, Kabbouche MA, O'Brien HL. Migraine. In: Kliegman RM, Stanton B, St. Geme J, Schor NF, editors. Nelson Textbook of Paediatrics. $20^{\text {th }}$ ed. Philadelphia, PA: Elsevier; 2016. p. 2866-73.

4. Gasbarrini A, Franceschi F, Gabrielli M, Fiore G, Candelli M, Zocco, et al. Helicobacter pylori infection and migraine: Possible role in aetiology and therapeutic implications. CNS Drugs 2000;13(2):97-101.

5. Van Hemert S, Breedveld AC, Rovers JM, Vermeiden JP, Witteman BJ,
Smits MG, et al. Migraine associated with gastrointestinal disorders: Review of the literature and clinical implications. Front Neurol 2014;5:241.

6. Li BU, Lefevre F, Chelimsky GG, Boles RG, Nelson SP, Lewis DW, et al. North American society for pediatric gastroenterology, hepatology, and nutrition consensus statement on the diagnosis and management of cyclic vomiting syndrome. J Pediatr Gastroenterol Nutr 2008;47:379-93.

7. Deleu D, Hanssens Y, Wotrhing EA. Symptomatic and prophylactic treatment of migraine: A critical reappraisal. Clin Neuropharmacol 1998;21:267-79.

8. Buture A, Gooriah R, Nimeri R, Ahmed F. Current understanding on pain mechanism in migraine and cluster headache. Anesth Pain Med 2016;6:e35190.

9. Gervil M, Ulrich V, Kaprio J, Olesen J, Russell MB. The relative role of genetic and environmental factors in migraine without aura. Neurology 1999;53:995-9.

10. Tunca A, Turkay C, Tekin O, Kargili A, Erbayrak M. Is Helicobacter pylori infection a risk factor for migraine? A case control study. Acta Neurol Belg 2004;104:161-4.

11. Su J, Zhou XY. Association between Helicobacter pylori infection and migraine: A meta-analysis. World J Gastroenterol 2014;20:14965-72.

12. Ali AM, Mohamed AM, Radwa AA. Helicobacter pylori infection and migraine. EC Paediatr 2017;5:80-6.

13. Poddar U, Thapa BR. Helicobacter pylori infection in children. Indian Pediatr 2000;37:275-83.

Funding: None; Conflict of Interest: None Stated.

How to cite this article: Shivalingaiah M, Kariyappa M, Hanumanna AK, Yelsangikar KR. Helicobacter pylori infection presenting as childhood recurrent headache: A case report. Indian J Child Health. 2019; 6(7):397-399.

Doi: 10.32677/IJCH.2019.v06.i07.017 